\title{
Thermal assessment of ambient pressure dried silica aerogel composite boards at laboratory and field scale
}

Roberto Garay Martinez ${ }^{1}$, Eunate Goiti ${ }^{1}$, Gudrun Reichenauer ${ }^{2}$, Shanyu Zhao ${ }^{3}$, Matthias Koebel ${ }^{3}$, Aitor Barrio ${ }^{1}$

Affiliation:

${ }^{1}$ Sustainable Construction Division, TECNALIA Research \& Innovation, Parque Tecnológico de Bizkaia, C/Geldo s/n, Edificio 700, E-48160 Derio Bizkaia Spain

${ }^{2}$ Bavarian Center for Applied Energy Research (ZAE Bayern), Magdalene-Schoch-Str. 3, 97074 Wuerzburg, Germany

${ }^{3}$ Building Energy Materials and components, Empa - Swiss Federal Laboratories for Materials Science and Technology, 8600 Dübendorf, Switzerland

* Corresponding Author. Tel.: +34 946430 069, E-mail Address:

Roberto.garay@tecnalia.com

In the context of increasing energy costs and the need for global reduction of $\mathrm{CO}_{2}$ emissions, the development of superinsulation materials for the construction sector allows the design of low-energy buildings. Since still being in an experimental or at early-commercial stage, $R \& D$ of these materials focused on its final application is required, to accelerate access to the market for renovation of the building stock where space is a critical metric.

In this paper, the experimental assessment of the thermal performance of a novel ambient pressure dried silica aerogel based composite is presented. In order to provide assessments at both, material and system levels, stress-strain tests, hot plate measurements, as well as full scale tests under realistic boundary conditions were conducted.

The overall results are that this material provides good insulation properties (thermal conductivity in the range of $0.015-0.018 \mathrm{~W} / \mathrm{mK}$ ), along with sufficient mechanical properties, and allows for the creation of superinsulating assemblies even at small wall thickness. 


\section{Introduction}

The development of cost-effective high thermal insulation performance products and systems can contribute to improve the energy efficiency of buildings and thus reducing $\mathrm{CO}_{2}$ emissions. The majority of energy in a building is spent to satisfy heating and cooling demands accounting for $70 \%$ of the total final energy use. The energy performance of an average European building is rather poor, due to the fact that a high percentage of the European residential buildings were constructed before the 1960s, when energy building regulations were very limited, and have not undergone renovations to improve energy performance, meaning that these buildings have low insulation levels and their systems are old and inefficient [1].

One key method to improve the energy efficiency of buildings is to enhance the thermal resistance of the envelope. This can be achieved by: $a$ ) increasing the thickness of traditional insulation materials, something that is not always possible, as often, there are space limitations; $b$ ) decreasing the thermal losses at given insulation thickness by using materials with significantly lower thermal conductivity, for example superinsulating materials such as aerogels. The use of Aerogel as an insulation material has been proven effective in several demonstration and retrofitting projects such as [2], the technical and economical optimization of façade insulation with Aerogel was studied in [3]. In [4] the design of an aerogel-filled sandwich panel was studied for building envelope integration.

Aerogels are open-porous, lightweight solids with densities ranging 3-350mg/ $\mathrm{cm}^{3}$ [5] consisting of an interconnected particle network structure with interstitial pores with a pore size typically $\ll 1 \mu \mathrm{m}[6,7]$. Such nanoporous structures make aerogels the materials with the lowest thermal conductivity at ambient conditions known in a solid ( $\lambda$ $\left.<0.012 \mathrm{Wm}^{-1} \mathrm{~K}^{-1}\right)[8,9]$.

Aerogels can be synthesized via a sol-gel process during which solid nanoparticles grow, crosslink and finally form a three-dimensional solid network with solvent filled pores. Since the silica aerogels comprise highly open structures in which the secondary particles of silica are connected to each other with only few siloxane bonds, the structure of native aerogels is too fragile to be handled. Aging processes are applied to strengthen the solid skeleton of silica [10].

Removal of solvent from the gel structure is essential for aerogel preparation, there are three typical routes to high performance aerogel-like materials: freeze drying [11], subcritical drying (or ambient pressure drying) $[12,13,14]$ and supercritical drying $[15$, $16,17]$. Freeze drying is not popular for silica aerogel synthesis, since it is addressed as a time and energy consuming process [18], and the formation of microscopic crystals during freeze could degrade the gel structure. Supercritical drying is the traditional route [19], which was first based on alcohols and today primarily on $\mathrm{CO}_{2}$, because of the latter system's greatly reduced process risks. Nowadays, ambient pressure drying of chemically modified gels results in materials with properties that are nearly indistinguishable from their supercritically dried analogs [20]. Thus, the supercritical and ambient pressure drying techniques tend to be applied for commercialization of aerogel materials. After drying, the nanosized pores in the system are filled with air leading to aerogels with a porosity greater than $90 \%$ [21]. 
Due to the exceptional properties of these materials they are excellent candidates for cases where the market demands products with strongly enhanced thermal insulation, better acoustic barrier and reduced weight properties [22].

Currently the main inhibitors that avoid spreading the use of superinsulating aerogel materials are: $(i)$ the high cost involved in their production and (ii) the poor mechanical properties of the associated current silica aerogel insulation products [23]. Cost reductions are mostly contingent on economical up-scaling and more efficient based on continuous and scalable production technologies. The largest savings which can be achieved from today's perspective are contingent upon a change of process technology from batch-type supercritical drying to a continuous subcritical ambient pressure drying process with complete solvent recycling and re-use.

The European Project AEROCOINs [24] has developed novel silica aerogel-based composite materials to improve the thermal insulation performance of the envelope of buildings aiming at maximizing their energy performance by reducing their energy demands. AEROCOINs has achieved the up-scaling of the formulations based on an ambient pressure drying process providing silica aerogel-based panels of $50 \mathrm{~cm} \times 50 \mathrm{~cm}$ x $2 \mathrm{~cm}$ dimensions which are compatible with critical performance levels in building regulations (e.g. fire reaction class $\mathrm{B}$ was obtained according to the Construction Products Regulation [25]).

In the present work, the main objective is to validate the thermal performance of novel ambient pressure dried aerogel composite at building scale. In order to provide experimental assessments not only at system but also at material level, stress-strain tests, hot plate measurements, as well as full scale tests under realistic boundary conditions were conducted.

The present work bases its thermal assessment process at building scale on several previous experimental an data analysis procedures for the experimental assessment of the energy performance of bulidings. In [25], a test was performed to calibrate a hygrothermal model of a wall with an insulating rendering based on silica-aerogels, for exterior thermal insulation applications. In [27] several envelope retrofitting solutions are tested, some of them comprising aerogel boards. The thermal transmittance of the system was assessed by different means: theoretical value, experimental by means of averaging and experimental by means of dynamic analysis with software LORD [28]. In this work, both experimental assessment methods are found to be in good agreement, although the theoretical transmittance of the wall is substantially lower- ca $20 \%$ - of the other two methods. Experimental assessments performed by dynamic methods based on system identification techniques such as those used by [28] and [29] are increasingly common within the last decades, in works such as [30] and [31].

In this particular work, the scope of the full scale experimental assessment was narrowed to the identification of the insulation properties of the aerogel material in the experiment. In order to better assess this performance, sensors were installed in close contact with both sides of these materials, on the inner side of a concrete wall-thus mitigating the effect of dynamic boundary conditions, and allowing for the correct application of averaging methods. 


\section{Preparation of Ambient-dried Aerogel composites}

A pre-polymerized form of tetraethoxysilane (TEOS) containing $20 \% \mathrm{w} / \mathrm{w} \mathrm{SiO}_{2}$ in ethanol (PEDS-P $75 \mathrm{E} 20$, PCAS, France) was used as the silica gel precursor. The precursor was diluted with ethanol (F25-AF-MEK ethanol with $2 \%$ methyl ethyl ketone) yielding a silica sol with $6 \% \mathrm{w} / \mathrm{w} \mathrm{SiO}_{2}$ content. After adding a $5.5 \mathrm{M}$ solution of ammonium hydroxide $\left(\mathrm{NH}_{4} \mathrm{OH}\right.$, Fluka, Germany) at $2 \% \mathrm{v} / \mathrm{v}$ of the sol, the activated sol was quickly transferred into a mold where the nonwoven polyester fiber blankets had been placed.

Two Polyester fiber (PES) blankets were used: $5 \times 5 \times 1 \mathrm{~cm}^{3}$ and $10 \times 10 \times 1 \mathrm{~cm}^{3}$ for labscale samples, $50 \times 50 \times 2 \mathrm{~cm}^{3}$ for pilot-scale samples. In both cases, delivered by Ridan Sp. z o.o, Poland.

Gelation of the silica resulted in the formation of a fiber reinforced gel composite. The aerogel composite board/ mat was obtained by surface modification (hydrophobization) of the aged gel by means of hexamethyldisiloxane followed by ambient pressure drying (APD) at $150^{\circ} \mathrm{C}$ for 3 hours in an oven. For comparison purposes, some aerogel composite materials were dried via supercritical drying (SCD) technique.

The impregnation of the PES blanket with the silica gel resulted in the air space between the fibers being filled out with a high porosity $(>90 \%)$, high surface area $(>600$ $\left.\mathrm{m}^{2} / \mathrm{g}\right)$, and low density $\left(0.08-0.12 \mathrm{~g} / \mathrm{cm}^{3}\right)$ silica aerogel material. In this way, a superinsulating composite material was obtained.

The use of the fiber based blanket as reinforcing matrix for the silica aerogel improves the cohesion and mechanical properties of the aerogel material, giving it more flexibility and reducing fracture/ cracking which is essential for building insulation applications. A photographic image of $10 \mathrm{~cm} \times 10 \mathrm{~cm}$ composites is shown in figure 1 .

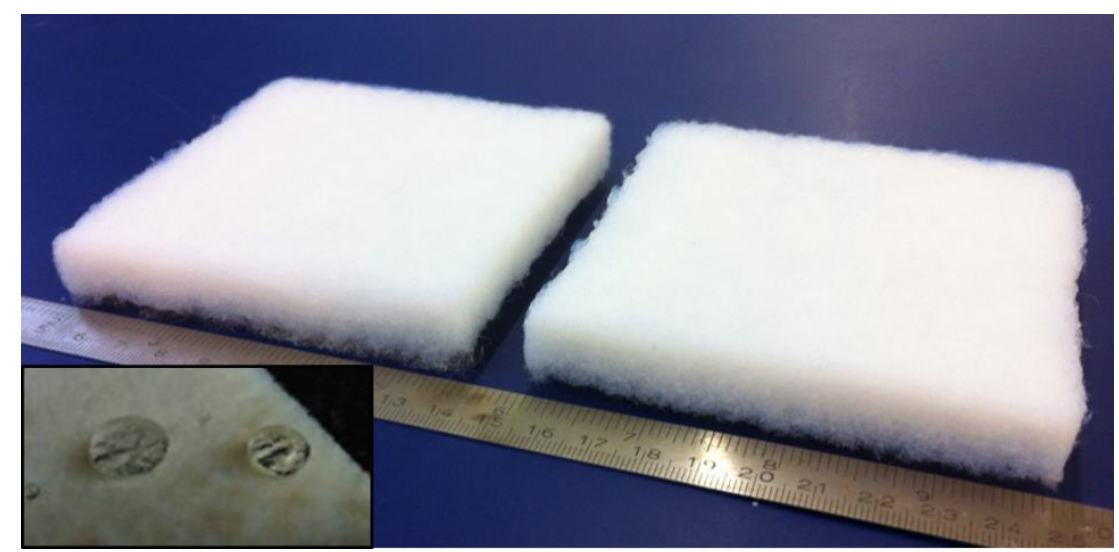

Figure 1. Digital photograph of the ambient dried PES-silica composite aerogels, inset shows the hydrophobicity of the composite

This synthesis process was followed at two different scales: Laboratory-scale and pilot manufacture plant scale.

At laboratory-scale, this process was assessed to be the most promising synthesis route for an upscaling process, and the pilot manufacture plant scale was the result of the upscaling of this process into a pre-industrial process. 
Samples were referenced with the following naming structure: PS-L-X for laboratory scale produced PES silica composite, for a given $\mathrm{X}$ batch; and PS-P-X for pilot manufacture plant produced PES silica composite, for a given $\mathrm{X}$ batch.

The physical properties of both lab-scale and pilot-scale manufactured aerogel composites are listed in Table 1 and Table 2, respectively.

\section{Characterization of the aerogel composites}

\subsection{Density and linear shrinkage}

The bulk density $\rho_{b u l k}$ was calculated from the weight and envelope volume of the square, quasimonolithic tiles. The linear shrinkage $L s(\%)$ upon drying was calculated from Eq. 1, based on the length of the wet $L_{w e t}$ and dried $L_{d r y}$ of aerogels:

$L_{S}=\frac{L_{w e t}-L_{d r y}}{V_{w e t}} \times 100$.

\subsection{Thermal conductivity of lab-scale prepared composites}

Thermal conductivities were determined for square plate specimens of monolithic aerogels using a custom built guarded hot plate device designed for small samples (guarded zone: $50 \times 50 \mathrm{~mm}^{2}$, measuring zone: $25 \times 25 \mathrm{~mm}^{2}$ ) of low thermal conductivity materials[32] at EMPA. The reliability of mentioned custom-built apparatus was verified by means of comparison with hot-wire measurement techniques at ZAEBayern.

The results of these tests are shown in Table 2. Compared with the reference silica aerogel at similar density prepared from PEDS-P ${ }_{75 E 20}\left(0.014 \mathrm{~W} \mathrm{~m}^{-1} \mathrm{~K}^{-1}\right)$ [33], the thermal conductivity of the respective composites, which are prepared under supercritical or ambient conditions, shows no significant changes with addition of PES fibers (from $0.0142-0.0160 \mathrm{~W} \mathrm{~m}^{-1} \mathrm{~K}^{-1}$ ).

\subsection{Mechanical property of the lab-scale prepared composites}

Mechanical characterization of the laboratory scale composites PS-L-1 through PS-L-4 was performed on monolithic cylindrical samples using an universal mechanical testing setup (Zwick/Z010, Zwick/Roell, Germany), equipped with a $2 \mathrm{kN}$ force transducer (KAP-S, AST Gruppe $\mathrm{GmbH}$, Germany) in a controlled environment $\left(23^{\circ} \mathrm{C}, 50 \%\right.$ relative humidity). Stress strain curves were measured in compression mode and elastic moduli were calculated from the linear regime of the curves which typically occurred at $4 \pm 2 \%$ strain. The samples were compressed with a constant deformation rate of 1 $\mathrm{mm} / \mathrm{min}$ up to $80 \%$ strain or until the first buckling event ( $>50 \%$ loss of stress) occurred. 
The strain-stress curves are shown in Figure 2. In comparison to a pure, monolithic PEDS-P ${ }_{75 E 20}$ aerogel of identical density $\left(100 \mathrm{~kg} / \mathrm{m}^{3}\right.$, final strength $\sim 2 \mathrm{MPa}$, elastic moduli $\sim 2 \mathrm{MPa}$ and strain at break $\sim 65 \%$ but with buckling before break [33]), the PESsilica composites displays a much lower elastic modulus of $0.26 \pm 0.13 \mathrm{MPa}$ and low final compressive strength $0.5-0.7 \mathrm{MPa}$ but a very high fracture strain of more than $80 \%$. This is due to the microfracturing which occurs during the ambient drying of the composites. Note that the supercritically dried reference silica aerogel also features a relatively high fracture strain $(65 \%)$ under laboratory conditions under a controlled compression rate, but is actually very fragile in real working conditions. As a result, the PES reinforcement not only facilitates ambient pressure drying, but also significantly improves cohesion of the fractured aerogel phase as well as flexibility and workability of the composite materials. The supercritically dried composite PS-L-2 is slightly stronger than the ambient dried samples (Figure 2, Table 2), which is attributed to fewer cracks formed during the drying process.

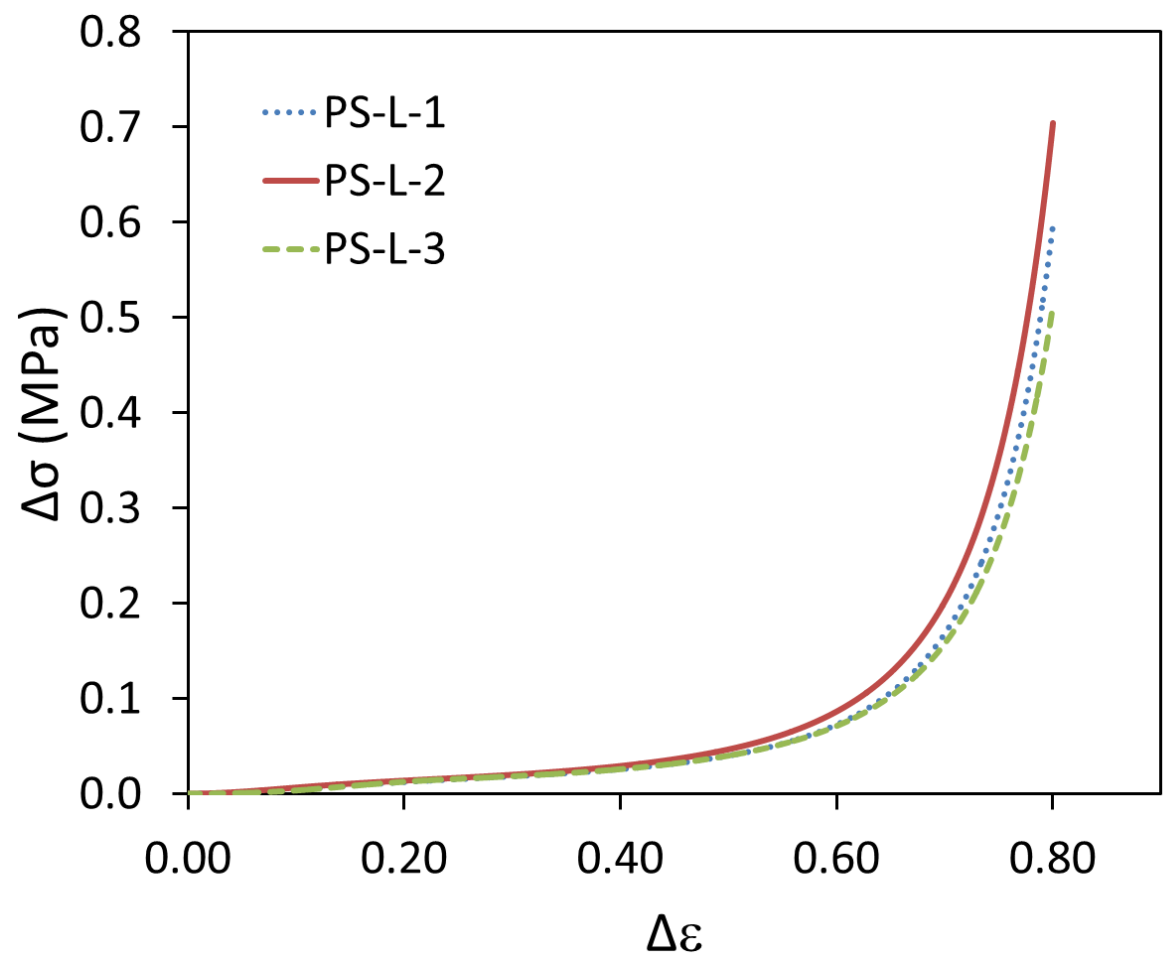

Figure 2. Strain-stress curve of the PES-silica composites.

\subsection{Thermal conductivity of pilot-scale produced composites}

Thermal testing of the pilot-scale produced silica aerogel composites was performed using two independent hot-plate measurement setups.

Boards with a size of $30 \mathrm{~cm} \times 30 \mathrm{~cm} \times 2 \mathrm{~cm}$ where characterized in terms of their thermal conductivity using a Netzsch HFM 436/3/1E instrument. This instrument establishes a selected temperature difference across the sample and determines the corresponding heat flow via two integrated heat flow meters. All experiments were performed at a mean temperature of about $22.5^{\circ}$ with a temperature gradient across the composite board of about $20{ }^{\circ} \mathrm{C}$. To avoid dust release and contamination of the instrument, the samples were wrapped in household type plastic foil before introducing them into the instrument for thermal analysis. 
Table 1 shows the results for two boards prepared under nominally identical conditions. In order to evaluate the possible effect of a mechanical deformation on the thermal performance of the silica aerogel based composites, the boards were exposed to a sequence of about four uniaxial compression cycles up to $20 \%$ strain before repeating the thermal conductivity measurement. The results reveal that no change in the thermal properties could be detected.

In addition, the same boards were analyzed again after being stored for one year in a laboratory environment (relative humidity $\mathrm{RH}<60 \%$ ). Again, no change in the thermal properties was detected within the range of the accuracy of the instrument. 
Table 1. Bulk density $\rho_{b u l k}$ and thermal conductivity $\lambda$ of pilot-scale produced composite boards.

\begin{tabular}{l|lllll}
\hline & pristine & & $\begin{array}{l}\text { after } \begin{array}{c}\text { 20 } \\
\text { mechanical } \\
\text { compression }\end{array} \\
\end{array}$ & $\begin{array}{l}\text { density } \\
\left(\mathrm{kg} / \mathrm{m}^{3}\right)\end{array}$ & $\begin{array}{l}\text { after storage for 1 year at } \\
\text { ambient conditions }\end{array}$ \\
& $\begin{array}{l}\text { conductivity } \\
(\mathrm{W} /(\mathrm{m} \mathrm{K})\end{array}$ & $\begin{array}{l}\text { thermal } \\
\text { conductivity } \\
(\mathrm{W} /(\mathrm{m} \mathrm{K})\end{array}$ & $\begin{array}{l}\text { thermal } \\
\text { conductivity } \\
(\mathrm{W} /(\mathrm{m} \mathrm{K})\end{array}$ & $\begin{array}{l}\text { density } \\
\left(\mathrm{kg} / \mathrm{m}^{3}\right)\end{array}$ \\
PS-P-1 & 94.0 & $0.018 \pm 0.001$ & $0.018 \pm 0.001$ & $0.017 \pm 0.001$ & 103.6 \\
PS-P-2 & 99.6 & $0.016 \pm 0.001$ & $0.016 \pm 0.001$ & $0.016 \pm 0.001$ & 108.1 \\
\hline
\end{tabular}

\subsection{Mechanical properties of pilot-scale produced composites}

Mechanical properties of ambient pressure dried composite boards were evaluated by means of compression tests that were performed using a Zwick Roell Z20 equipped with a $20 \mathrm{kN}$ load cell. PS-P1 and PS-P2 composite boards cut to a size of about $24 \mathrm{~cm}$ x $27 \mathrm{~cm}$ and a thickness of about $2 \mathrm{~cm}$ where placed between two square plane parallel plates of $34 \mathrm{~cm}$ lateral length. While one of the plates was fixed, the other was movable with a centrally positioned ball joint to ensure that only axial forces were applied to the samples. Displacement and force were measured continuously with an accuracy of \pm 0.5 $\mathrm{mm}$ and $\pm 1 \%$ (for loads $>60 \mathrm{~N}$ ), respectively.

According to EU standard EN 826 (Determination of Compression Behavior of Thermal Insulation Products) [34] samples were placed centrally between the two plates, preloaded with $(250 \pm 10) \mathrm{Pa}$ and compressed with a constant rate of displacement of 5 $\mathrm{mm} / \mathrm{min}$. The zero deformation point was defined as the deformation at a stress of $(250 \pm 10) \mathrm{Pa}$. In contrast to the standard, where deformations of $10 \%$ are recommended for evaluation of elastic constants, the aerogel boards were compressed up to strain levels of $25 \%$.

Only at very low deformation $(<2 \%)$ and around $25 \%$ strain a linear increase of the stress strain curve was observed (Figure 3). This is a typical behavior found for aerogels, as they tend to soften after an initial Hooke's law dependence since relatively small deformations result in buckling of the backbone at the nanoscopic scale.

To quantify the respective Young's modulus, $E=\Delta \sigma / \Delta \varepsilon$, the derivative of the stressstrain curve was determined at two different deformations of $2 \%$ and $25 \%$, respectively. $\Delta \sigma$ denotes the relative stress (pressure applied) and $\Delta \varepsilon=\left(\Delta \mathrm{d} / \mathrm{d}_{0}\right)$ the relative strain (i.e. relative change in sample thickness $\Delta \mathrm{d} / \mathrm{d}_{0}$ ) in the linear (elastic) regime. As compared to the traditional insulation [35, 36], the PES reinforced aerogel boards show a low compressive strength at $10 \%$ strain and low Young's modulus, but relative higher ultimate compressive strength. Overall, such ambient dried silica aerogel composite with the reinforcement of PES blanket ameliorates both low thermal conductivity and improved ultimate compressive strength of the silica aerogels, giving more flexibility and adaptability of superinsulating aerogel materials for building insulation applications. 


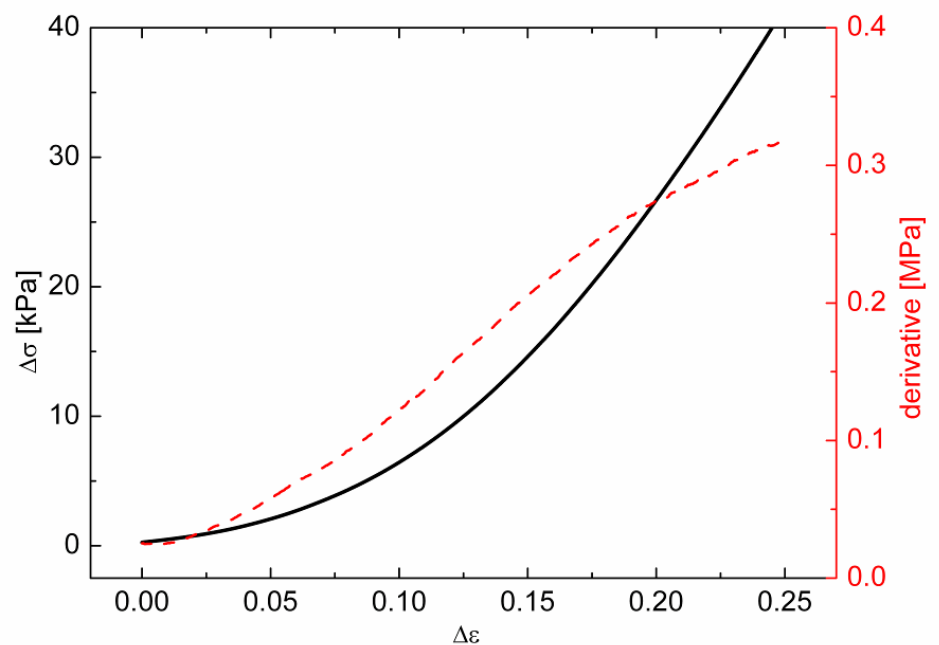

Figure 3. Black: Typical stress strain curve recorded for the silica composite boards. Red: corresponding derivative.

Table 2. Bulk density $\rho_{b u l k}$, linear shrinkage $L_{s}(E q .1)$, thermal conductivity $\lambda$ and elastic moduli $E$ of the lab-scale produced composites

\begin{tabular}{lllllll}
\hline Samples & $\begin{array}{l}\text { Drying } \\
\text { method }\end{array}$ & $\begin{array}{l}\text { Size } \\
(\mathrm{mm})\end{array}$ & $\begin{array}{l}\text { pbulk } \\
(\mathrm{kg} / \mathrm{m} 3)\end{array}$ & $\begin{array}{l}\text { Ls } \\
(\%)\end{array}$ & $\begin{array}{l}\lambda \\
(\mathrm{W} \text { m-1K-1) }\end{array}$ & $\begin{array}{l}\mathrm{E} \\
(\mathrm{MPa})\end{array}$ \\
\hline PS-L-1 & APD & $50 \times 50 \times 10$ & 114.0 & 3.2 & 0.0160 & 0.24 \\
PS-L-2 & CO2 SCD & $50 \times 50 \times 10$ & 100.0 & 2.3 & 0.0139 & 0.39 \\
PS-L-3 & APD & $100 \times 100 \times 10$ & 102.0 & 2.3 & 0.0145 & 0.14 \\
PS-L-4 & APD & $100 \times 100 \times 10$ & 103.0 & 2.5 & 0.0142 & - \\
\hline
\end{tabular}

Table 3. Elastic moduli determined in different regimes of deformation for two pilot-scale silica composite boards.

\begin{tabular}{l|ll}
\hline & at $2 \%$ deformation & at $25 \%$ deformation \\
& $\mathrm{E}(\mathrm{MPa})$ & $\mathrm{E}(\mathrm{MPa})$ \\
\hline PS-P-1 & $0.0150 \pm 0.0001$ & $0.32 \pm 0.0005$ \\
PS-P-2 & $0.0250 \pm 0.00002$ & $0.32 \pm 0.0007$ \\
\hline
\end{tabular}




\section{Fire reaction characterization}

The fire reaction characterization was carried out under construction European standard for euroclass fire classification EN13501-1:2007 [37]. According to this standard, the reaction to fire classification of a product for walls must be tested according to single burning item test (SBI) test [38] under the same installation conditions as those envisaged for the final applications. Hence, a sample of two wings $(1,5 \mathrm{~m} \times 1,0 \mathrm{~m}$ and $1,5 \mathrm{~m} \times 0,5 \mathrm{~m}$ ) was built with prefabricated elements as defined in section 5.2. The joints were protected by gypsum plaste and the corner was mounted just by supporting the short wing with the long wing. This unprotected junction is the most unfavorable case because it allow the flame to reach the otherwise hidden part of the system.
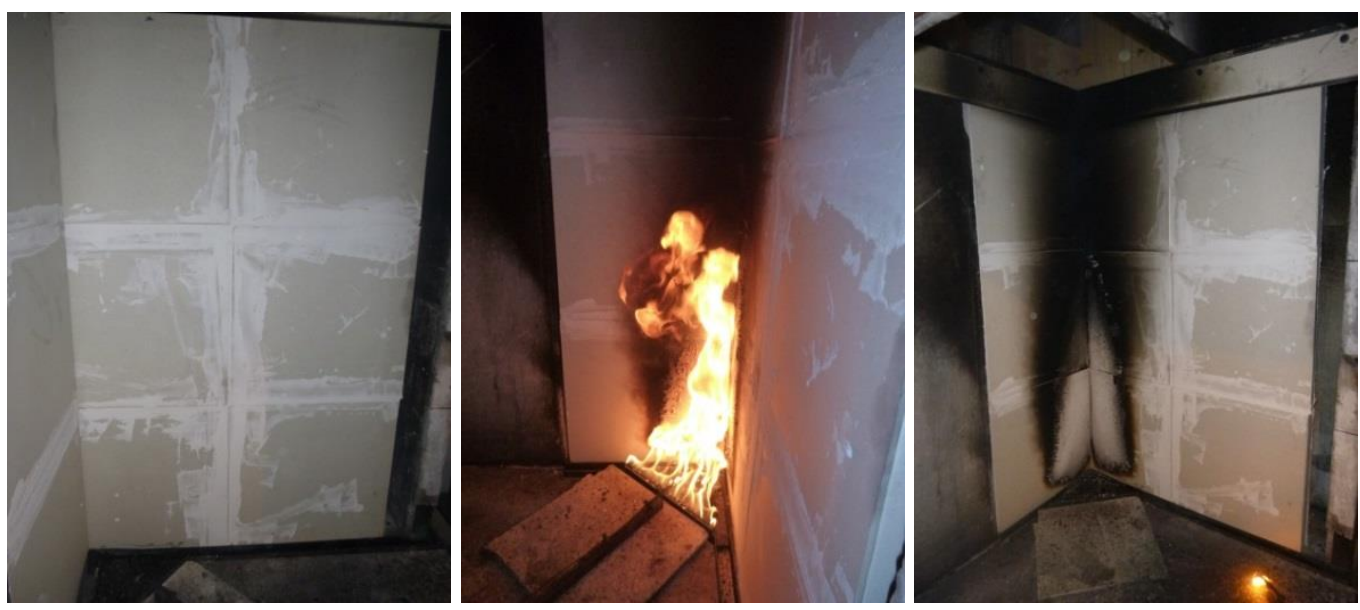

Figure 4. Images of the sample before (left), during (center) and after SBI test (right).

The main parameters for the classification of the system are included in the following table:

Table 4. SBI main parameter results of prototype.

\begin{tabular}{|c|c|c|c|c|c|}
\hline $\begin{array}{l}\text { THR } \\
{[M J]}\end{array}$ & $600 s$ & FIGRA $0.2 \mathrm{~W} / \mathrm{s}$ & FIGRA $0.4 \mathrm{~W} / \mathrm{s}$ & $\begin{array}{ll}T S P & 600 s \\
{\left[m^{2}\right]} & \end{array}$ & $\begin{array}{l}\text { SMOGRA } \\
{\left[\mathrm{m}^{2} / \mathrm{s}^{2}\right]}\end{array}$ \\
\hline 0.85 & & 20.560 & 6.182 & 49.658 & 6.192 \\
\hline
\end{tabular}

These figures indicates that the combustible materials (plastic composite and insulation layers) were not affected by the flame and were protected by the plasterboard.

According to [38], the final performance of this system was classified as B-s1,d0. This classification is suitable for installation of the Aerogel-based internal insulation system in buildings, under all major construction regulations in Europe. 


\section{Full scale experiment}

\subsection{Experimental Environment}

Building scale validation of the insulation performance of the composite boards PS-P-X was carried out in the adaptive Kubik by Tecnalia (hereinafter referred to as KUBIK) fullscale building test facility [39], which served at the same time as a technological demonstration environment, and as a full scale experimentation and validation testing environment for performance assessment of these composites under real-life conditions.
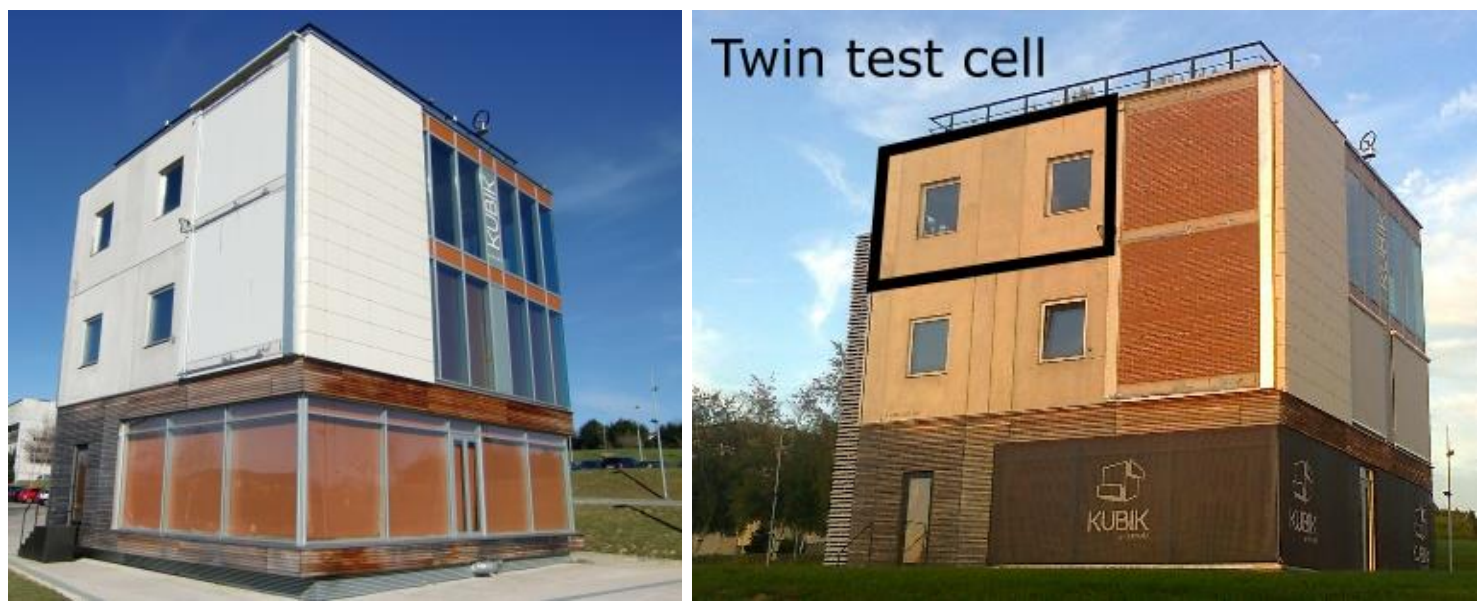

Figure 5. South-West view of the KUBIK test facility (left) and location of the test cell for testing of indoor insulation systems (right).

The KUBIK building is located in Derio, Spain $\left(43^{\circ} 17^{\prime} \mathrm{N} 2^{\circ} 52^{\prime} \mathrm{W}\right)$, in the vicinity of the city of Bilbao, and approximately $12-15 \mathrm{~km}$ from the sea. KUBIK is a full scale experimental R\&D infrastructure to demonstrate energy efficient technologies, focused on the development of new products and systems. The main distinctive feature of KUBIK is its capacity to create realistic scenarios for the quantitative determination of energy efficiency/ energy savings resulting from the interplay of constructive solutions, intelligent management of HVAC and lighting systems as well as non-renewable and renewable energy sources. The infrastructure is a building with a total floor area of 500 $\mathrm{m}^{2}$ distributed over basement, ground floor and two upper levels.

To create an ideal test environment for the aerogel based composite insulation system, a subset of the KUBIK building was selected. The selected space consists of a relatively large test cell on the second floor of the KUBIK test building. This test cell provides two equally exposed façade modules, allowing the installation of insulation system. Indoor temperature control was achieved by means of a heating and cooling system. The system is composed of two fan-coil HVAC units installed at roof level, and a controller which delivers, on demand, heating \& cooling to the test cell with the added functionality that dynamic control scenarios such as steps, ramps and schedules can be programmed. The homogeneity of ambient temperature inside the room is evaluated by means of a distribution of temperature sensors in various locations across the test cell: Two stands are distributed on the N-S axis, where three Pt-100 temperature sensors are placed at 10, 110 and $170 \mathrm{~cm}$ height, respectively. 
This environment has been used for testing of various insulation materials and systems since its construction in 2014, as multiple systems can be tested at the same time in portions of the exposed wall. The Aerogel-based insulation system was installed in roughly $1 / 2$ of the available surface, while other tests have been conducted in the remaining space. During the measurement phase and analysis process, several issues were inspected: 1-D heat transfer, 2-D thermal field on the installed support structure (plastic-composite profiles), and constructive details of the area in the vicinity of the window.

\subsection{Definition of test samples}

The prototypes used in the assessment consisted of a multi-layer assembly with the following components (see Figure 5):

- $\quad$ Reflective foil (on the side facing the pre-existing wall)

- Two aerogel composite boards

- Plasterboard (on the side facing the room interior)

These elements were prefabricated in a plastic-composite frame providing mechanical stability to the system and allowing a dry construction process. These prototypes were manufactured by Acciona Infraestructuras, Madrid. Prototypes were delivered in two sizes: Small $(50 \mathrm{~cm} \times 50 \mathrm{~cm})$ and Large $(50 \mathrm{~cm} \times 100 \mathrm{~cm})$.

\subsection{Assessment of 1-D heat transfer}

The ambient dried Aerogel composite boards developed in this work are insulation materials which are characterized by their extremely low thermal conductivity as well as a comparatively low density and heat capacity. The utilization of insulation materials in the construction sector has the primary function to generate highly insulated building envelopes, while a reduced heat capacity is of little interest, and commonly disregarded in thermal calculations such as [40], furthermore considering that buildings are constructed with large quantities of materials such as concrete and bricks, with much greater heat capacity.

For this reason, the thermal assessment focused on the characterization of the on-site thermal resistance - $\mathrm{R}$ - of the tested aerogel based components. Along with the thermal transmittance, thermal resistance is used in the building and construction industry [41] as the most widely accepted reference parameter for the thermal insulation properties of materials, components and entire construction elements. Under uniform conditions the thermal resistance is the ratio of the temperature difference across a material $\left(T_{1}-T_{2}\right)$ and the heat flux through it $(\mathrm{Q})$ per unit area. Thermal resistance varies with temperature but it is common practice in construction to treat it as a constant value.

In order to obtain the R-value of the insulation system, temperature sensors were installed on both surfaces of the system:

- Directly on the internal surface of the pre-existing façade (outer surface of the insulation system),

- On the internal surface of the insulation system. 
Heat flux sensors were installed on the internal surface of the render, in direct contact with the air in the test cell. This set-up was replicated along 4 selected measurement axes, where all variables were measured separately. These measurement locations were selected to account for the possible variability in the test outcome as a result of variations in the production process and unexpected temperature variations.

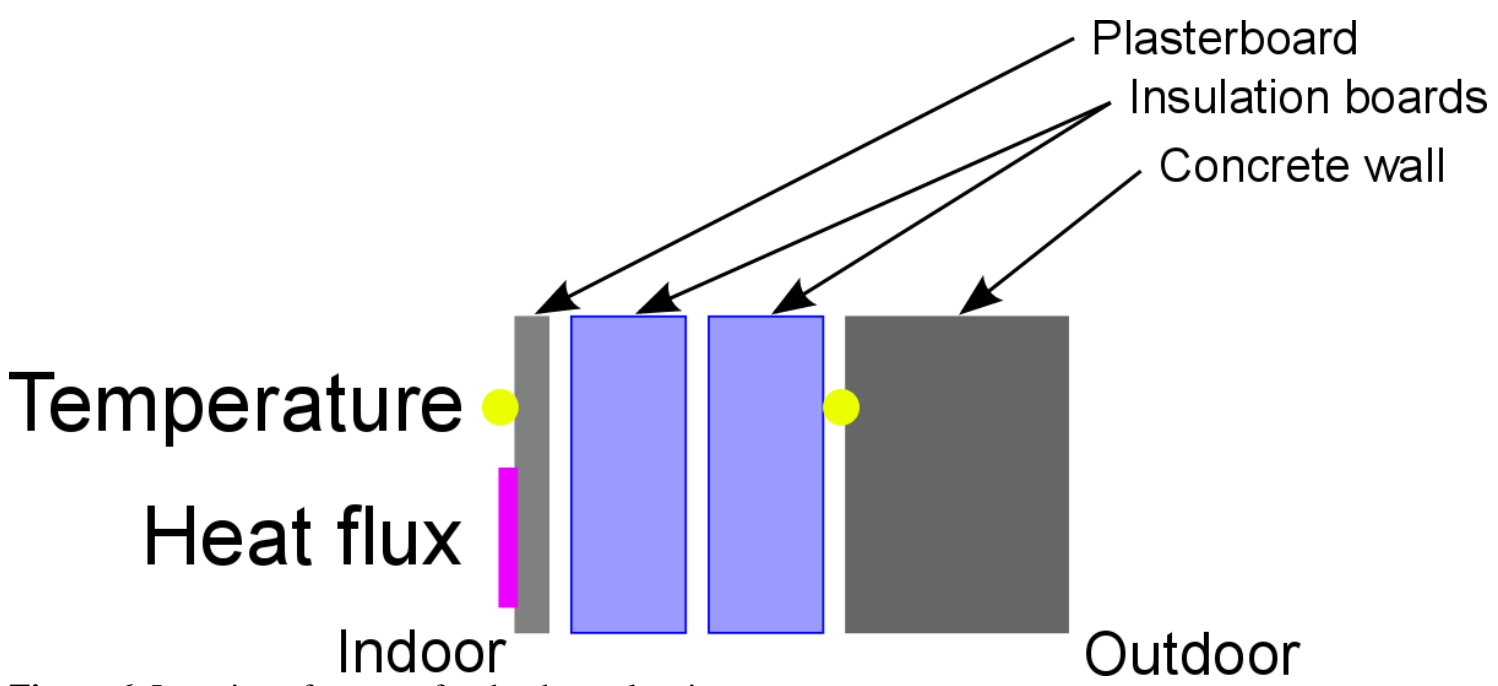

Figure 6. Location of sensors for the thermal resistance measurements

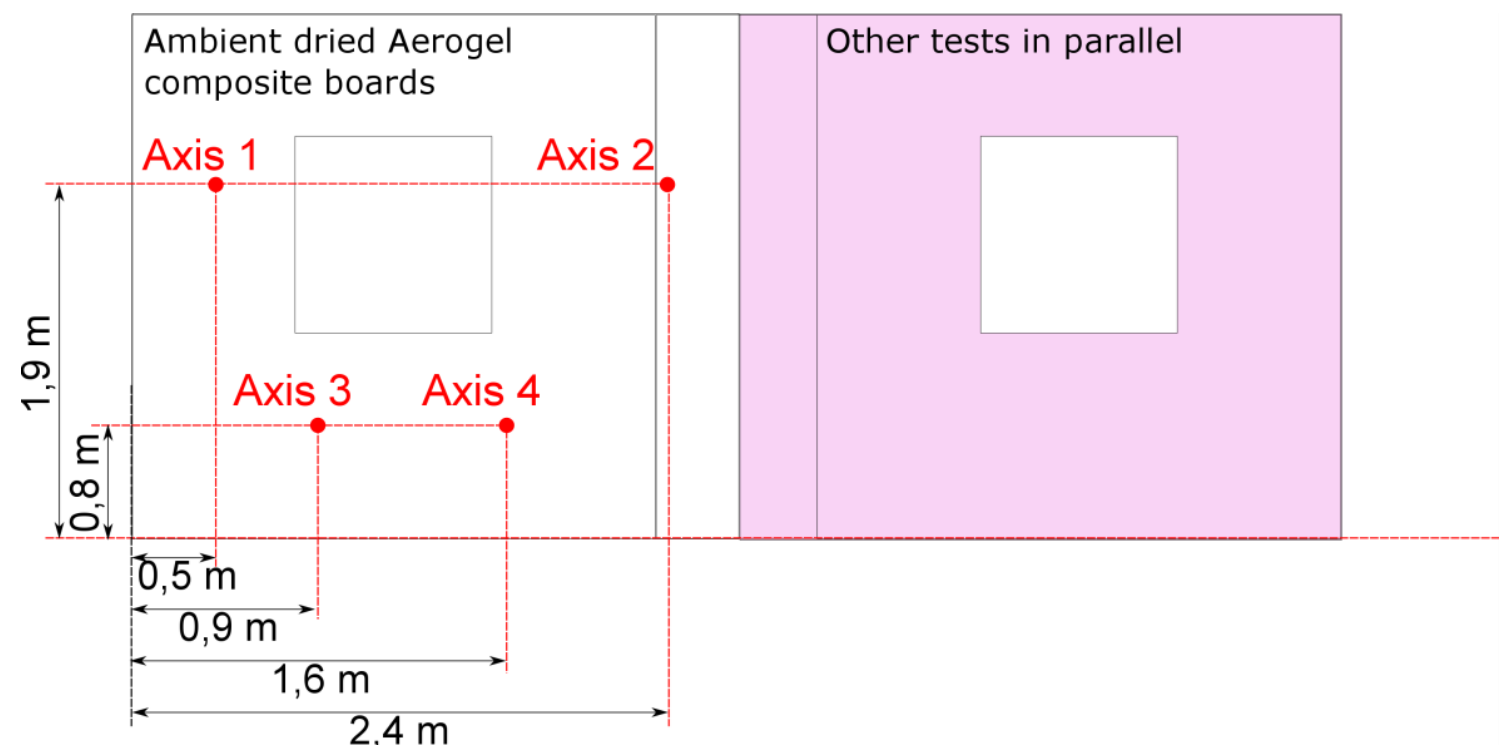

Figure 7. Internal view of the location of measurement axes in the test wall. 
The R-value provides a steady-state characterization of the thermal insulation performance. As such steady-state characterization, R-value measurements must be performed under situations where the steady-state assumption can be guaranteed. For on-site measurements, reference [42] states that the stability should be addressed by ensuring that the daily averaged R-value does not deviate by more than $5 \%$ from that from the previous $24 \mathrm{~h}$. However, this criterion is established for on-site measurements, where heavy limitations on the campaign length are imposed by the construction process itself or the final handover of the building to the owner. Being a research facility, where the campaign length was not limited by such practical constraints and where the internal boundary conditions could be set specifically by means of the advanced control systems, the tests reported here were earmarked by a stability which was far better, i.e. deviations which were significantly lower than the reference 5\% stated above.

\subsection{Test campaign}

The test campaign consisted on several test sequences in the period from November 2014 to April 2015. Sequences were almost consecutive with the exception of a period lasting approximately 6 weeks in January 2015, where the test was stopped due to maintenance and adaptation works in KUBIK.

Table 5. Indoor boundary conditions during the different tests conducted.

\begin{tabular}{l|lll}
\hline Id & Indoor temperature & Period & \\
\hline 1 & $30^{\circ} \mathrm{C}$ & $14 / 11 / 2014$ & $24 / 11 / 2014$ \\
2 & $30^{\circ} \mathrm{C}$ & $24 / 11 / 2014$ & $01 / 12 / 2014$ \\
3 & $15^{\circ} \mathrm{C} / 25^{\circ} \mathrm{C}$ oscillation every $12 \mathrm{~h}$ & $01 / 12 / 2014$ & $09 / 12 / 2014$ \\
4 & $15^{\circ} \mathrm{C} / 25^{\circ} \mathrm{C}$ oscillation every 6h & $09 / 12 / 2014$ & $16 / 12 / 2014$ \\
5 & $30{ }^{\circ} \mathrm{C}$ & $05 / 01 / 2015$ & $02 / 02 / 2015$ \\
6 & $24 \mathrm{~h} \mathrm{Sequence:}$ & $19 / 02 / 2015$ & $02 / 03 / 2015$ \\
& $00: 00->27^{\circ} \mathrm{C}$ & & \\
& $07: 00->25^{\circ} \mathrm{C}$ & $02 / 03 / 2015$ & $06 / 04 / 2015$ \\
7 & $24 \mathrm{~h} \mathrm{Sequence:}$ & & \\
& $00: 00->17^{\circ} \mathrm{C}$ & $06 / 04 / 2015$ & $04 / 05 / 2015$ \\
& $07: 00->25^{\circ} \mathrm{C}$ & & \\
\hline 8 & $00: 00->27^{\circ} \mathrm{C}$ & & \\
& $07: 00->25^{\circ} \mathrm{C}$ & & \\
\hline
\end{tabular}




\subsection{Test campaign results}

From the raw-series, surface-to-surface R-value calculations were made for each of the measurement axes. Overall, two sets of results are provided, namely:

- Daily averaged R-values (figure 8): Minutely logged signals were averaged on a daily basis (0h-24h). $1 \mathrm{R}$-value per day is provided.

- Cumulated R-value (figure 9): Minutely logged signals were cumulated (first data set onwards). The corresponding $\mathrm{R}$-value is calculated for each point in time. The statistical confidence of this cumulated R-value increases with time.

In both cases, and due to its greater physical meaning, the thermal conductance (the inverse of the R-value) is plotted. The thermal conductance provides the direct heat loss across the construction for a given temperature gradient per unit surface area.

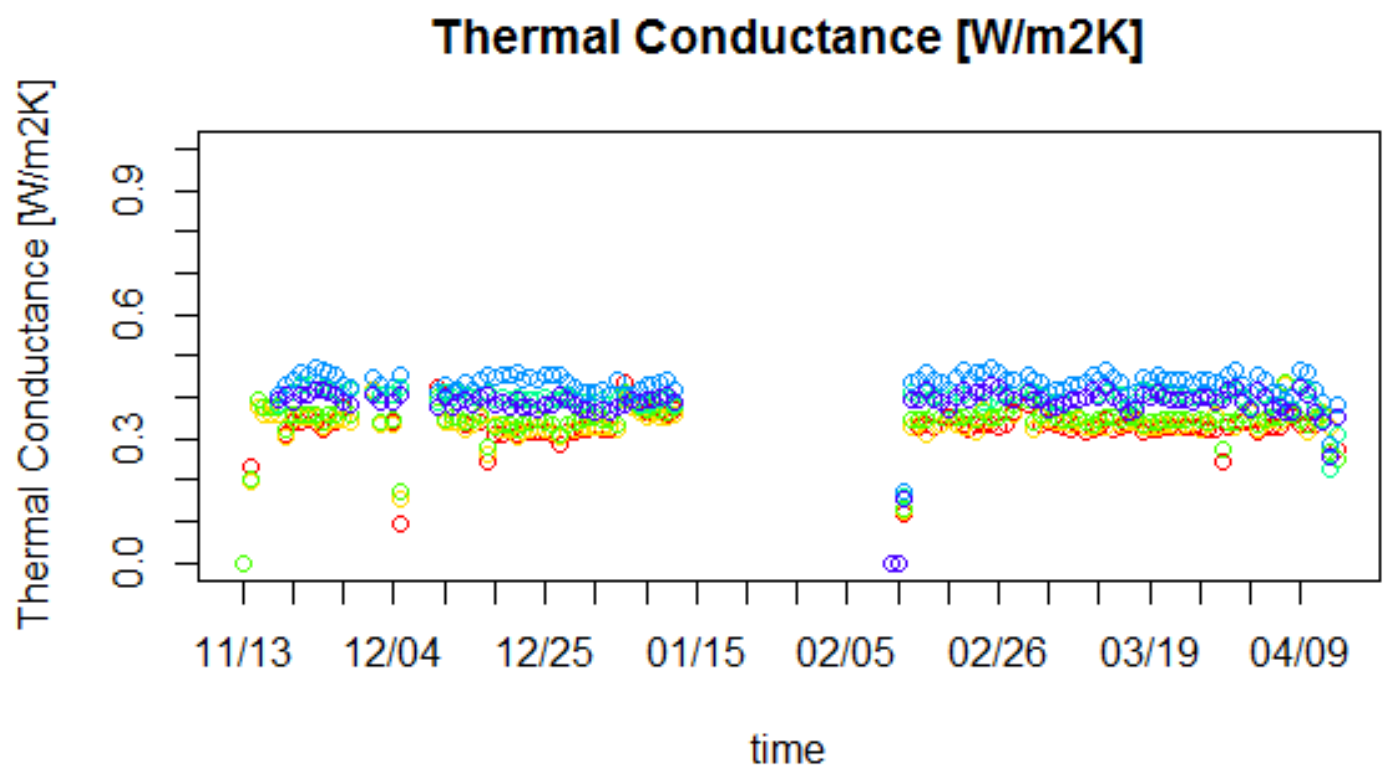

Figure 8. Daily coupling coefficients in the period 2014/11-2015/04. 


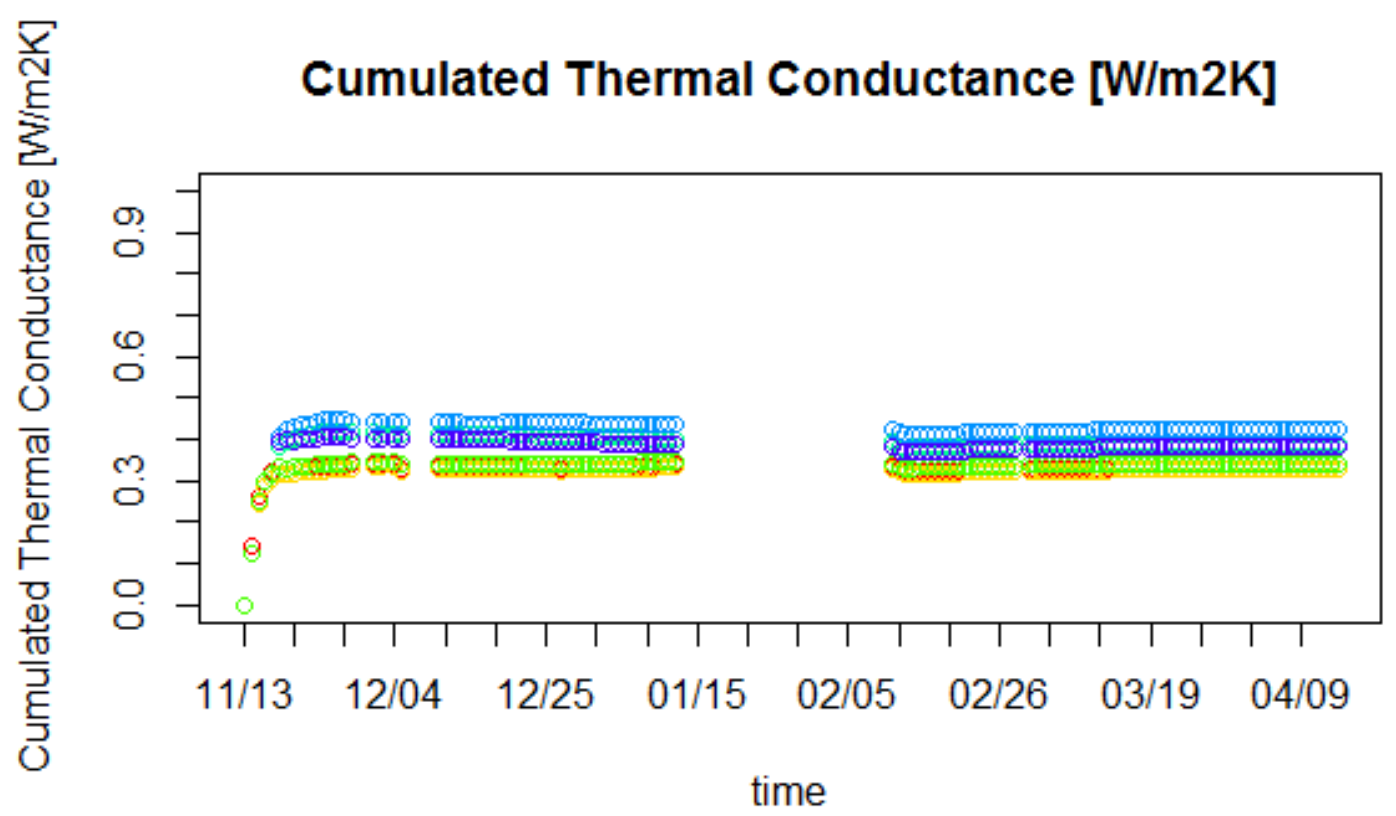

Figure 9. Cumulated coupling coefficients in the period 2014/11-2015/04.

As it can be directly observed from the above figures, there is a certain variation in the daily coupling coefficients, which is particularly relevant for certain peak days. A careful assessment of these outliers has shown that they have occurred on days, when data logger failure had occurred or only partial datasets of the full $24 \mathrm{~h}$ cycle had been recorded. Another type of outlier was connected to a few single days where the internal boundary conditions had been changed as a result of switching between scenarios (e.g. indoor temperature is artificially increased from $15^{\circ} \mathrm{C}$ to $25^{\circ} \mathrm{C}$ in sequences $3 \& 4$ ).

However, in the long term, the cumulated coupling coefficient calculation procedure proved to be very stable. Considering datasets from 100 days of measurements, sufficient inertia was included in the results to allow us to neglect any transient or momentary thermal storage effects of the building envelope itself.

Table 6. Experimentally determined coupling coefficients from the four axes.

\begin{tabular}{ll|llll}
\hline Axis & 1 & 2 & 3 & 4 \\
\hline $\begin{array}{l}\text { Thermal } \\
{\left[\mathrm{W} / \mathrm{m}^{2} \mathrm{~K}\right]}\end{array}$ & Conductance & 0.308 & 0.327 & 0.328 & 0.341 \\
\hline
\end{tabular}


Based on the reported values of the coupling coefficients, a reverse calculation was made to obtain the thermal conductivity of the ambient dried Aerogel composite boards (Table 7).

Table 7. R-value of Aerogel-based insulation system and estimated and thermal conductivity of the embedded Aerogel composites.

\begin{tabular}{l|llll}
\hline Axis & 1 & 2 & 3 & 4 \\
\hline R-value $[\mathrm{m} 2 \mathrm{~K} / \mathrm{W}]$ & 2.872 & 2.688 & 2.676 & 2.561 \\
Thermal conductivity $[\mathrm{W} / \mathrm{mK}]$ & 0.0139 & 0.0149 & 0.0149 & 0.0156 \\
\hline
\end{tabular}

\section{Conclusions}

An efficient ambient pressure drying process has allowed the up-scaling manufacture of aerogel boards. Designing and fabricating a novel building component prototype based on the developed aerogel based reinforced composites has yield a component compatible with integration in internal insulation processes of building envelopes by means of conventional construction methods. This building component integrates lowconductive plastic-composite profiles and plasterboard renders within a multi-layer arrangement, and it has obtained the best fire classification for organic materials: B$\mathrm{s} 1, \mathrm{~d} 0$.

The thermal performance of the insulating component under real conditions has been demonstrated in a relevant construction environment. A monitorization campaign has been performed over roughly 6 months and the main conclusion of the full scale testing is that the aerogel board, when integrated into building envelope retrofitting activities performs as a superinsulation component, as several measurements provided thermal conductivities within the range of thermal conductivity measured at laboratory scale, thus, in the range of $0.015-0.017 \mathrm{~W} / \mathrm{mK}$.

\section{Acknowledgments}

Research leading to these results were funded within the $7^{\text {th }}$ EU Framework Program, under grant agreement no. 260141, AEROCOINS project.

\section{References}

[1] BPIE. Europe's buildings under the microscope. Executive summary, 2011. ISBN: 9789491143014

[2] K. Ghazi Wakili, B. Binder, M. Zimmermann, Ch. Tanner, Efficiency verification of a combination of high performance and conventional insulation layers in retrofitting a 130-year old building, Energy and Buildings (2014), 82, 237-242

[3] Erdem Cuce, Pinar Mert Cuce, Cristopher J. Wood, Saffa B. Riffat, Optimizing insulation thickness and analysing environmental impacts of aerogel-based thermal superinsulation in buildings, Energy and Buildings (2014), 77 28-39 
[4]K. Chen, A Neugebauer, T. Goutierre, A. Tang, L. Glicksman, L.j. Gibson, Mechanical and thermal performance of aerogel-filled sandwich panels for building insulation, Energy and Buildings (2014, 76, 336-346

[5] AP Rao, AV Rao, GM Pajonk, Hydrophobic and Physical Properties of the Two Step Processed Ambient Pressure Dried Silica Aerogels with Various Exchanging Solvents, J Sol-Gel Scie Technol 2005, 36(3):285-292.

[6] H.-P. Ebert, Thermal properties of Aerogels, in: M.A. Aegerter, N. Leventis, M.M. Koebel (Eds.) Aerogels Handbook, Springer Science+Business Media, New York, 2011, pp. 537-564;

[7] JL Gurav, IK Jung, HH Park, ES Kang, DY Nadargi, Silica aerogels: synthesis and applications, J Nanomaterials 2010, 2010

[8] CJ Brinker, GW Scherer, (1990), Sol-gel science: The physics and chemistry of solgel processing. San Diego: Academic Press.

[9] Aerogels Handbook, Eds. MA Aegerter, N Leventis, MM Koebel, Springer, Heidelberg, (2011).

[10] S. Hæreid, M. Dahle, S. Lima, M.-A. Einarsrud, Preparation and properties of monolithic silica xerogels from TEOS-based alcogels aged in silane solutions, J. NonCryst. Solids 1995, 186: 96-103.

[11] J C Brinker, G W Scherer, Sol-Gel Science, The Physics and Chemistry of Sol-Gel Processing, ed. s. Edition. 1990, New York: Academic Press.

[12] M. Schmidt, F. Schwertfeger, Applications for silica aerogel products, Journal of Non-Crystalline Solids, 225 (1998) 364-368.

[13] V.D. Land, T.M. Harris, D.C. Teeters, Processing of low-density silica gel by critical point drying or ambient pressure drying, Journal of Non-Crystalline Solids, 283 (2001) 11-17.

[14] A. Parvathy Rao, G.M. Pajonk, A.V. Rao, Effect of preparation conditions on the physical and hydrophobic properties of two step processed ambient pressure dried silica aerogels, Journal of Materials Science, 40 (2005) 3481-3489.

[15] F Graser, A Stange, Preparation of aerogels. 1987, US Patents.

[16] C A García-González, M C Camino-Rey, M Alnaief, et al. Supercritical drying of aerogels using $\mathrm{CO} 2$ : Effect of extraction time on the end material textural properties . The Journal of Supercritical Fluids, 2012, 66(0): 297-306. 
[17] M J Bommel, A B Haan. Drying of silica gels with supercritical carbon dioxide . Journal of Materials Science, 1994, 29(4): 943-948.

[18] Y Liu, Y Zhao, X Feng. Exergy analysis for a freeze-drying process . Applied Thermal Engineering, 2008, 28(7): 675-690.

[19] MA Aegerter, N. Leventis, M.M. Koebel, (2011) Aerogels handbook., Springer.

[20] M.M. Koebel, L. Huber, S. Zhao, W.J. Malfait, Breakthroughs in cost-effective, scalable production of superinsulating, ambient-dried silica aerogel and silicabiopolymer hybrid aerogels: from laboratory to pilot scale, J Sol-Gel Sci Technol, 2016 $1-11$.

[21] A Emmerling, J Fricke, Scaling properties and structure of aerogels, Journal of SolGel Sci Technol 1997, 8: 781-788.

[22] R Baetens, BP Jelle, A Gustavsen, Aerogel insulation for building applications: a state-of-the-art review, Energy and Buildings 2011, 43(4): 761-769.

[23] H Maleki, L Duraes, A Portugal, A new trend for development of mechanically robust hybrid silica aerogels, Materials Letters 2016, 179: 206-209,

[24] AEROCOINS, Aerogel-Based Composite/Hybrid Nanomaterials for Cost-Effective Building Super-Insulation Systems, EU FP7, GA 260141. http://www.aerocoins.eu $(2015 / 11 / 16)$

[25] Construction Products Regulation, Regulation (EU) No 305/2011 of the European Parliament and of the Council of 9 March 2011 laying down harmonized conditions for the marketing of construction products and repealing Council Directive 89/106/EEC Text with EEA relevance

[26] Ibrahim, M.; Wurtz, E.; Biwole, P.H.; Achard, P.; Sallee, H.; Hygrothermal performance of exterior walls covered with aerogel-based insulating rendering. Energy and Buildings 2014, 84, 241-251

[27] Galliano, R.; Ghazi Wakili, K.; Stahl, Th.;Binder, B.; Baniotti, B.; Performance evaluation of aerogel-based and perlite-based prototyped insulations for internal thermal retrofitting: HMT model validation by monitoring at demo scale. Energy and Buildings 2016, 126, 275-286

[28] Gutschker, O.; Parameter identification with the software package LORD, Building and Environment, Special Issue: Outdoor Testing, Analysis and Modelling of Building Components, 2008, 43(2), 163-169

[29] CTSM-R Development Team, Continuous Time Stochastic Modeling in R. User's Guide and Reference Manual, 2015. http://ctsm.info/pdfs/ctsmr-reference.pdf (2016-0614) 
[30] Strachan, P.A.; Vandaele, L. Case studies of outdoor testing and analysis of building components. Building and Environment, 2008, 43(2), 129-142.

[31] Naveros, I.; Bacher, P.; Ruiz, D.P.; Jiménez, M.J.; Madsen, H.; Setting up and validating a complex model for a simple homogeneous wall, Energy and Buildings, 2014, 70, 303-317

[32] Stahl, T.; Brunner, S.; Zimmermann, M.; Ghazi Wakili, K., Thermo-hygric properties of a newly developed aerogel based insulation rendering for both exterior and interior applications. Energy and Buildings 2012, 44 (0), 114-117.

[33] Wong, J. C. H.; Kaymak, H.; Brunner, S.; Koebel, M. M., Mechanical properties of monolithic silica aerogels made from polyethoxydisiloxanes. Microporous Mesoporous Mater. 2014, 183 (0), 23-29.

[34] EN 826:1996. Thermal insulating products for building applications Determination of compression behavior.

[35] Spitzner, M.H., Gellert, R., Pfundstein, M., Rodolphi, A. Dämmstoffe: Grundlagen, Materialien, Anwendungen, Walter De Gruyter, 2007.

[36] Gellert, R., Inorganic mineral materials for insulation in buildings. In Materials for Energy Efficiency and Thermal Comfort in Buildings, Woodhead Publishing, 2010, 193-228.

[37] EN 13501-1:2007+A1:2010. Fire classification of construction products and building elements. Part 1: Classification using data from fire reaction tests

[38] EN 13823:2010, Reaction fire tests for Building products. Building products excluding floorings exposed to thermal attack by a single burning item.

[39] Garay, R et Al, Energy efficiency achievements in 5 years through experimental research in KUBIK, 6th International Building Physics Conference, IBPC 2015, Torino, 2015

[40] EN ISO 6946: 2007. Building components and building elements - Thermal resistance and thermal transmittance - Calculation Method

[41] EN ISO 7345:1987 Thermal insulation -- Physical quantities and definitions

[42] EN ISO 9869-1:2014 Thermal insulation -- Building elements -- In-situ measurement of thermal resistance and thermal transmittance -- Part 1: Heat flow meter method 